\title{
Assessment of the performance of a compact concentric spectrometer system for Atmospheric Differential Optical Absorption Spectroscopy
}

\author{
C. Whyte ${ }^{1}$, R. J. Leigh ${ }^{1}$, D. Lobb ${ }^{2}$, T. Williams ${ }^{2}$, J. J. Remedios ${ }^{1}$, M. Cutter ${ }^{2}$, and P. S. Monks ${ }^{3}$ \\ ${ }^{1}$ Earth Observation Science, Space Research Centre, Department of Physics \& Astronomy, University of Leicester, \\ University Road, Leicester, LE1 7RH, UK \\ ${ }^{2}$ Surrey Satellite Technology Ltd., Rayleigh House, 1 Bat \& Ball Road, Sevenoaks, TN14 5LJ, UK \\ ${ }^{3}$ Department of Chemistry, University of Leicester, University Road, Leicester, LE1 7RH, UK
}

Received: 23 July 2009 - Published in Atmos. Meas. Tech. Discuss.: 6 August 2009

Revised: 6 November 2009 - Accepted: 22 November 2009 - Published: 7 December 2009

\begin{abstract}
A breadboard demonstrator of a novel UV/VIS grating spectrometer has been developed based upon a concentric arrangement of a spherical meniscus lens, concave spherical mirror and curved diffraction grating suitable for a range of atmospheric remote sensing applications from the ground or space. The spectrometer is compact and provides high optical efficiency and performance benefits over traditional instruments. The concentric design is capable of handling high relative apertures, owing to spherical aberration and comma being near zero at all surfaces. The design also provides correction for transverse chromatic aberration and distortion, in addition to correcting for the distortion called "smile", the curvature of the slit image formed at each wavelength. These properties render this design capable of superior spectral and spatial performance with size and weight budgets significantly lower than standard configurations. This form of spectrometer design offers the potential for exceptionally compact instrument for differential optical absorption spectroscopy (DOAS) applications from LEO, GEO, HAP or ground-based platforms. The breadboard demonstrator has been shown to offer high throughput and a stable Gaussian line shape with a spectral range from 300 to $450 \mathrm{~nm}$ at $0.5 \mathrm{~nm}$ resolution, suitable for a number of typical DOAS applications.
\end{abstract}

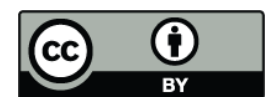

Correspondence to: P. S. Monks (p.s.monks@le.ac.uk)

\section{Introduction}

Measurement of atmospheric species with climate change or air quality (AQ) implications is a key driver for ground and space-based Earth Observation. Techniques such as differential optical absorption spectroscopy (DOAS) (Platt, 1994; Edner et al., 1993; Evangelisti et al., 1995; Veitel et al., 2002; Hönninger et al., 2004; Lohberger et al., 2004; Lee et al., 2005; Friess et al., 2005; Sinreich et al., 2005) operating in the UV/Visible bandwidth have been used over a number of decades for the retrieval of atmospheric concentrations of such key parameters as ozone $\left(\mathrm{O}_{3}\right)$ (Axelsson et al., 1990; Virkkula, 1997; Wang et al., 2006; Kim et al., 2007b), nitrogen dioxide $\left(\mathrm{NO}_{2}\right)$ (Van Roozendael et al., 1994; Leser et al., 2003; Pundt et al., 2005; Palazzi et al., 2007; Louban et al., 2008; Kramer et al., 2008), formaldehyde (HCHO) (Cardenas et al., 2000), the halogen oxides (bromine monoxide (BrO) (Richter et al., 1999; Aliwell et al., 2002; Hönninger and Platt, 2002; Bobrowski et al., 2003; Bobrowski and Platt, 2007), chlorine dioxide (OClO) (Tornkvist et al., 2002; Kuhl et al., 2006), iodine monoxide (IO) (Wittrock et al., 2000; Friess et al., 2001), and the oxygen dimer $\left(\mathrm{O}_{4}\right)$ (Wagner et al., 2004; Friess et al., 2006) from which information on the atmospheric aerosol profile can be retrieved.

$\mathrm{NO}_{2}, \mathrm{O}_{3}$, and $\mathrm{HCHO}$ are factors in air quality with impacts on human health, specifically being implicated in impaired lung function (Bonay and Aubier, 2007; D'Amato et al., 2005; Galan et al., 2003; Kim et al., 2007a; MacNee and Donaldson, 2000; Peel et al., 2007; Rage et al., 2006; Chance et al., 2000). In most scenarios the primary anthropogenic source of $\mathrm{NO}_{2}$ is vehicular emission (Eskes et al., 2006). Typical concentrations of $\mathrm{NO}_{2}$ range

Published by Copernicus Publications on behalf of the European Geosciences Union. 
from $10-45 \mathrm{ppbV}$, elevated to $200 \mathrm{ppbV}$ during high pollution episodes (DEFRA, 2007). Ozone is a secondary pollutant generated through the sunlight initiated oxidation of VOCs, including formaldehyde in the presence of nitrogen oxides $\left(\mathrm{NO}_{\mathrm{x}}\right)$. Typical concentrations are $15 \mathrm{ppbV}$, elevated to over $100 \mathrm{ppbV}$ in hot and sunny conditions (DEFRA, 2007). Formaldehyde (and aldehydes in general) (Wayne, 2000) and glyoxal $\left(\mathrm{C}_{2} \mathrm{H}_{2} \mathrm{O}_{2}\right)$ (Hastings et al., 2005) have been implicated in the formation of components that produce photochemical smog.

There is a requirement for accurate measurement of such atmospheric species at high spatio-temporal resolution to accurately determine fluxes and map transport. Furthermore, to provide data for use in regional forecasting and monitoring it is necessary to investigate the planetary boundary layer at a spatial resolution suitable for assimilation into mesoscale models, often $2 \mathrm{~km}$ by $2 \mathrm{~km}$ or less (Cai et al., 2002; Harrison et al., 2006; Mihailovic et al., 2005; Owen et al., 1999). The use of satellite data in such initiatives is constrained by difficulties in the retrieval of data from the PBL owing to the presence of clouds. A high spatial resolution significantly increases the likelihood of cloud free pixels that could be recorded, while simultaneously providing data on a quasiurban scale $(2-10 \mathrm{~km})$. The abundance of many AQ species is driven by photochemistry, showing significant diurnal variability, requiring systems with low noise and high throughput which offer relatively high temporal resolution. Compact instruments capable of providing the necessary optical performance and spectral resolution to make meaningful measurements of these target species are a key enabling technology.

In 1994 a design for a new type of optical concentric spectrometer based on an Offner relay spectrometer was published by (Lobb, 1994). A standard Offner spectrometer consists of three spherical concentric mirrors: two concave and one convex, sometimes with an added concentric meniscus lens. The object and image surfaces are typically in a common plane that includes the common centre of curvature (Prieto-Blanco et al., 2006). Lobb's configuration uses a single concave spherical mirror (from which light is reflected twice) and a spherical meniscus lens. The convex mirror is replaced by a convex spherical diffraction grating. The spectrally-dispersed image is again in the same plane as the common centre. The grating pattern lines are in equi-spaced parallel planes orthogonal to the focal plane (Lobb, 2004). A schematic diagram of such a system is given in Fig. 1. This concept could allow for a high performance imaging spectrometer of a considerably reduced size compared to equivalent instrumentation (in a Czerny-Turner configuration for example).

The beam from the entrance slit is folded at a flat mirror and passes through the meniscus lens, where it is then reflected by the concave mirror, and falls on the grating. A first order diffracted beam forms the useful spectral image from the second reflection at the concave spherical mirror and second transmission through the meniscus lens. The de-

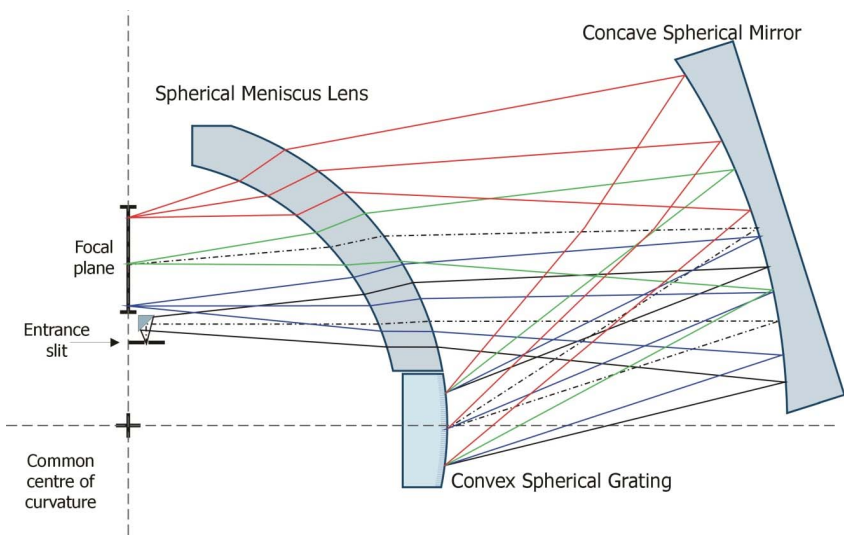

Fig. 1. The Lobb design for a novel reduced size concentric spectrometer. This diagram is adapted from Lobb, 2004.

sign requires a grating frequency in the order of $>2000$ cycles/mm for UV/Visible applications and features relatively large diffractive deflections, which makes the system compact with an intrinsic stability of wavelength calibration. This optical arrangement inherently leads to near zero spherical aberration (Lobb, 2004). Full details can be found in (Lobb, 1994), with discussions on the application of concentric spectrometers to earth viewing systems given in Lobb (2004) and Bovensmann et al. (2002).

The concentric spectrometer concept could provide a compact and powerful instrument for differential optical absorption spectroscopy (DOAS) applications for ground based observations, high altitude platforms (HAP) or for satellite imaging. This paper details the characterisation of the first DOAS demonstrator of this novel concentric spectrometer system, including details on the optical components and an appraisal of the performance of the instrument in comparison to target specifications.

\section{Performance specification of the concentric spectrometer demonstrator}

This spectrometer was first proposed for geostationary space flight as part of a ESA study in 2005 (Burrows, 2005), however the technology had not previously been practically demonstrated. A goal for the current demonstrator was to take the optical design and apply it to potential flight opportunities. As such the demonstrator was designed as a representation of a low earth orbit system with daily global coverage (swath width $2600 \mathrm{~km}$ ) to meet the criteria of the upcoming ESA Sentinel 5 mission (Langen, 2007), as derived from the air quality drivers of the ESA CAPACITY report (Composition of the Atmosphere: Progress to Applications in the user CommunITY) (Kelder et al., 2005), which examined the intentions of planned space missions against the needs of the GMES (Global Monitoring for Environment and Security) users. 
The demonstrator was therefore conceived as a broadband imaging spectrometer with the primary objective of the detection of the key air quality significant atmospheric species: $\mathrm{NO}_{2}$ and tropospheric $\mathrm{O}_{3}$ over a bandwidth of 300-450 nm. This bandwidth would also permit the detection of other important trace gases, such as $\mathrm{HCHO}$, glyoxal and $\mathrm{BrO}$ and provide a measure of the aerosol optical thickness through retrievals of the oxygen dimer, $\mathrm{O}_{4}$. The emphasis on the detection of atmospheric compounds with significance to air quality monitoring resulted in this novel spectrometer being attributed with the acronym Compact Air Quality Spectrometer, or CompAQS.

The design was to represent a LEO imaging system with global daily coverage to meet the Sentinel 5 requirements. The target nadir ground resolution was set to $5 \times 5 \mathrm{~km}$ with a swath width of $2500 \mathrm{~km}$ to provide global daily coverage, which in the demonstrator correlated to an entrance slit of $52 \mathrm{~mm}$ length consisting of 500 resolved elements $90 \mu \mathrm{m}$ in size. The target along-track resolution and orbit constrain the sampling time to less than $0.8 \mathrm{~s}$. The target spectral resolution was $0.5 \mathrm{~nm}$, sufficient for DOAS retrievals of the target species, with a sampling factor of 7 pixels per FWHM to assess the instrument line shape in both spectral and spatial domains. Taking these factors into account the CompAQS demonstrator was designed with a focal plane consisting of 2048 spectral pixels, giving spectral sampling of $0.075 \mathrm{~nm}$ per pixel, and 4096 spatial pixels with a corresponding spatial sampling of $13 \mu \mathrm{m}$ ( $650 \mathrm{~m}$ from LEO) per pixel. The relative aperture at the slit was $f / 3.06$ in the spectral domain, $f / 1.25$ in the spatial domain, and the spectrometer had unit magnification, such that the width of the entrance slit was the same as the FWHM of a resolved spectral element on the focal plane. The target specifications described above determine the size and layout of the CompAQS demonstrator as the size of the optical components, including the radius of curvature of the grating, lens and mirror, scale linearly with the size of the focal plane. A comparison of the target specifications of the CompAQS space system against the Sentinel 5 requirements and other relevant existing or planned systems is given in Table 1.

The detector package used in the demonstrator was an $22 \mathrm{~V}$ CCD47-20 Back Illuminated CCD sensor with a $1.3 \times 1.3 \mathrm{~cm}$ active area detector, comprising an array of $1024 \times 1024$, $13 \times 13 \mu \mathrm{m}$ pixels, with an associated electron capacity of up to 100000 electrons per pixel. This pixel size determined the focal plane to be $27.6 \times 55.2 \mathrm{~mm}$ in size. The CCD was translated through a $2 \times 4$ array to map the full focal plane. Owing to the spatial relationship between the optical components and the size of the focal plane the resultant dimensions for the arrangement of the optical components and the focal plane are little over $20 \mathrm{~cm}^{3}$.

\section{Component specification}

\subsection{Diffraction grating}

Of the bespoke optical elements the diffraction grating had the most exacting manufacturing tolerances owing to its impact on instrument throughput, with the lowest transmission of all the optical components and the strongest potential for stray light if not manufactured accurately. To provide the necessary spectral sampling over the bandwidth of the CompAQS demonstrator the grating required a grating frequency of $2350 \pm 1$ cycles $/ \mathrm{mm}$. The grating was manufactured by Carl Zeiss Optronics $\mathrm{GmbH}$ from a fused silica substrate provided by Comar Instruments (UK), polished to an RMS smoothness of $0.40 \mathrm{~nm}$ across the optical surface. The diffraction efficiency was relatively uniform for nonpolarised light across the bandwidth, with a mean efficiency of $60 \%$ from the half-sinusoidal profile. Analysis performed by Carl Zeiss showed that the error in the groove direction was \pm 0.06 degrees. The micro-roughness of the grating surface was evaluated by Carl Zeiss using AFM measurements made across the surface. The mean micro roughness, $\sigma$, was $0.93 \mathrm{~nm}$ with an intrinsic error of $\pm 0.1 \mathrm{~nm} \mathrm{rms}$. To provide a cursory evaluation into the quality of the grating the total integrated scatter $\left([4 \pi \sigma / \lambda]^{2}\right)$ from the grating surface was calculated across the bandwidth and was shown to vary smoothly from approximately $0.15 \%$ at the lower end of the target bandwidth to approximately $0.07 \%$ at the upper end of the bandwidth. The grating marks a significant achievement in that a high-quality, technically demanding grating can be manufactured on a convex surface with a relatively small radius of curvature for implementation in this novel technology.

\subsection{Spherical meniscus lens, concave spherical mirror and fold mirror}

The spherical lens and mirror were manufactured by the Florida based company Coastal Optical Systems (US), fabricated from fused silica. The lens was anti-reflection coated; measurements on each side of the lens showed that the reflectivity was below $0.5 \%$ over the majority of the bandwidth, with a local minimum of approximately $0.01 \%$ between 350 and $400 \mathrm{~nm}$ and a maximum of approximately $0.9 \%$ at $450 \mathrm{~nm}$, at which point the reflectivity rose sharply outside of the demonstrator bandwidth. The mirror was coated with a dielectric-protected aluminium layer provided by Universal Thin Film Labs. The reflective coating gave a total reflectivity of between 91 and $93 \%$ over the bandwidth, with the local maximum at approximately $350 \mathrm{~nm}$. The optical surfaces of each item were analysed by Coastal Optical Systems using optical interferometry. The front surface of the lens was measured to have a RMS micro-roughness of $0.417 \mathrm{~nm}$ while the rear surface had a value of $0.276 \mathrm{~nm}$. While there has been no appraisal of the subsurface quality 
Table 1. Comparison of the spectral and spatial sampling requirements of the proposed ESA Sentinel 5 mission against current and future satellite systems that aim to deliver the same data products, and the projected specification of the concentric spectrometer (Van der A et al., 2000; Callies et al., 2000; Munro and Eisinger, 2006; Flynn et al., 2005; Graf et al., 1999; Rodriguez et al., 2002; Stuhlmann et al., 2005).

\begin{tabular}{|c|c|c|c|c|c|c|c|c|}
\hline & & & & & Data Product & & & \\
\hline & Specification & $\mathrm{O}_{3}$ & $\mathrm{SO}_{2}$ & $\mathrm{HCHO}$ & Halogen Oxides & $\mathrm{O}_{4}$ & AOD & $\mathrm{NO}_{2}$ \\
\hline 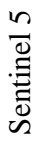 & $\begin{array}{l}\text { Spatial Res (nadir) / km } \\
\text { Spectral Res / nm } \\
\text { SNR }\end{array}$ & $\begin{array}{c}5 \times 5 \\
0.5 \\
1000\end{array}$ & $\begin{array}{c}5 \times 5 \\
0.5 \\
1000\end{array}$ & $\begin{array}{c}5 \times 5 \\
0.5 \\
1000\end{array}$ & $\begin{array}{c}5 \times 5 \\
0.5 \\
1000\end{array}$ & $\begin{array}{c}5 \times 5 \\
0.5 \\
1500\end{array}$ & $\begin{array}{c}5 \times 5 \\
0.5 \\
1500^{*}\end{array}$ & $\begin{array}{c}5 \times 5 \\
0.5 \\
1050\end{array}$ \\
\hline$\sum_{0}$ & $\begin{array}{l}\text { Spatial Res (nadir) / km } \\
\text { Spectral Res / nm } \\
\text { SNR }\end{array}$ & $\begin{array}{c}13 \times 24 \\
0.5 \\
265\end{array}$ & $\begin{array}{c}13 \times 24 \\
0.5\end{array}$ & $\begin{array}{c}13 \times 24 \\
0.5 \\
1450\end{array}$ & $\begin{array}{c}13 \times 24 \\
0.5 \\
700\end{array}$ & $\begin{array}{c}13 \times 24 \\
0.5 \\
1400\end{array}$ & $\begin{array}{c}13 \times 24 \\
0.5 \\
>500\end{array}$ & $\begin{array}{c}13 \times 24 \\
0.5 \\
2600\end{array}$ \\
\hline$\sum_{0}^{\infty}$ & $\begin{array}{l}\text { Spatial Res (nadir) / km } \\
\text { Spectral Res / nm } \\
\text { SNR }\end{array}$ & $\begin{array}{c}49 \times 50 \\
1 \\
1000\end{array}$ & $\begin{array}{c}49 \times 50 \\
1 \\
1000\end{array}$ & $\begin{array}{l}1 \\
1 \\
1\end{array}$ & $\begin{array}{l}1 \\
1 \\
1\end{array}$ & $\begin{array}{l}1 \\
1 \\
1\end{array}$ & $\begin{array}{c}49 \times 50 \\
1 \\
1000\end{array}$ & $\begin{array}{c}49 \times 50 \\
1 \\
1000\end{array}$ \\
\hline$\sum_{0}^{N}$ & $\begin{array}{l}\text { Spatial Res (nadir) / km } \\
\text { Spectral Res / nm } \\
\text { SNR }\end{array}$ & $\begin{array}{c}40 \times 40 \\
0.28 \\
/\end{array}$ & $\begin{array}{l}1 \\
1 \\
1\end{array}$ & $\begin{array}{l}1 \\
1 \\
1\end{array}$ & $\begin{array}{c}40 \times 40 \\
0.28 \\
/\end{array}$ & $\begin{array}{l}1 \\
1 \\
1\end{array}$ & $\begin{array}{c}40 \times 40 \\
0.28 \\
/\end{array}$ & $\begin{array}{c}40 \times 40 \\
0.28 \\
/\end{array}$ \\
\hline U & $\begin{array}{l}\text { Spatial Res (nadir) / km } \\
\text { Spectral Res / nm } \\
\text { SNR }\end{array}$ & $\begin{array}{l}6 \times 6 \\
0.41 \\
850\end{array}$ & $\begin{array}{l}6 \times 6 \\
0.41 \\
850\end{array}$ & $\begin{array}{l}6 \times 6 \\
0.41 \\
2000\end{array}$ & $\begin{array}{l}6 \times 6 \\
0.41 \\
2000\end{array}$ & $\begin{array}{l}1 \\
1 \\
1\end{array}$ & $\begin{array}{l}1 \\
1 \\
1\end{array}$ & $\begin{array}{l}6 \times 6 \\
0.41 \\
2500\end{array}$ \\
\hline 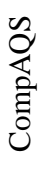 & $\begin{array}{l}\text { Spatial Res (nadir) /km } \\
\text { Spectral Res / nm } \\
\text { SNR }\end{array}$ & $\begin{array}{c}5 \times 5 \\
0.5 \\
1000 \\
(3000)\end{array}$ & $\begin{array}{c}5 \times 5 \\
0.5 \\
1000 \\
(3000)\end{array}$ & $\begin{array}{c}5 \times 5 \\
0.5 \\
1200 \\
(3500)\end{array}$ & $\begin{array}{c}5 \times 5 \\
0.5 \\
1200 \\
(3500)\end{array}$ & $\begin{array}{c}5 \times 5 \\
0.5 \\
1500 \\
(4000)\end{array}$ & $\begin{array}{c}5 \times 5 \\
0.5 \\
1200 \\
(3500)\end{array}$ & $\begin{array}{c}5 \times 5 \\
0.5 \\
2500 \\
(6000)\end{array}$ \\
\hline
\end{tabular}

* Taken from CAPACITY report (Kelder et al., 2005).

/ represents no data available. GOME-2 has a swath width of $960 \mathrm{~km}$, MTG is geostationary.

of the lens the total integrated scatter has been reasonably assumed to be less than $0.1 \%$ across the bandwidth accounting for light passing twice through the lens in the instrument (from source to grating, from grating to detector). The RMS micro-roughness of the finished optical surface of the concave mirror was found to be $0.491 \mathrm{~nm}$, giving a total integrated scatter under $0.09 \%$ over the bandwidth, again accounting for light reflecting twice off the mirror surface.

The fold mirror was provided by SP3 Plus (UK), again made from fused silica with a reflective aluminium and protective dielectric coating, with a specified surface polish of $1 \mathrm{~nm}$. The total reflectivity was measured to be between approximately 92 and $92.5 \%$ across the bandwidth, with the local maximum appearing at approximately $440 \mathrm{~nm}$. The combined total integrated scatter for the current instrument is given in Table 2 .
The estimated total integrated scatter of the instrument is shown to decrease with increasing wavelength, and these values can provide a rough estimate of the total fraction of stray light that may be generated from the optical components, with $0.28 \%$ to $0.51 \%$ of the total incident photons deviating from the intended light path, of which a portion may terminate at the focal plane. Stray light is a significant issue for scattered sunlight systems such as this: as a demonstrator for a LEO system CompAQS was designed to work with typical Earth spectral radiance levels, which increases over the bandwidth by some three orders of magnitude (Kelder et al., 2005) from $1.7 \times 10^{11}$ to $1.5 \times 10^{14}$ photons $/\left[\mathrm{cm}^{2}\right.$. s.sr.nm]. Thus stray light from longer wavelength radiation can obscure the weaker, lower wavelength radiation, leading to poor quality data from the UV channels. This current iteration of the concentric spectrometer was intended primarily as a 
Table 2. Estimated total integrated scatter for CompAQS instrument evaluated from the total contribution from each component, assuming a worst case scenario of $0.1 \%$ from the lens in the absence of subsurface quality information.

\begin{tabular}{lccccccc}
\hline \multirow{2}{*}{ Component TIS Contribution / \% } & \multicolumn{7}{c}{ Wavelength / nm } \\
& 300 & 320 & 350 & 370 & 400 & 425 & 450 \\
\hline Grating & 0.1518 & 0.1293 & 0.1115 & 0.0971 & 0.0854 & 0.0756 & 0.0674 \\
Lens & 0.1 & 0.1 & 0.1 & 0.1 & 0.1 & 0.1 & 0.1 \\
Spherical Mirror & 0.0846 & 0.0721 & 0.0622 & 0.0541 & 0.0476 & 0.0422 & 0.0376 \\
Fold Mirror & 0.1755 & 0.1542 & 0.1289 & 0.1153 & 0.0987 & 0.0874 & 0.0780 \\
\hline Instrument Total Integrated Scatter / \% & 0.5118 & 0.4556 & 0.4026 & 0.3666 & 0.3316 & 0.3052 & 0.2830 \\
\hline
\end{tabular}

demonstrator of the concentric spectrometer concept and as such the overall quality of the components is not necessarily representative of the requirements of a true space instrument.

\section{Characterization of the CompAQS demonstrator}

The following section describes the experiments to investigate and characterise the demonstrator system, and the outcomes of this analysis in comparison to the target performance.

This demonstrator does not include an entrance telescope system. Light enters the instrument through a square-conical baffle with the entrance slit at the apex of the cone. Two entrance slits were used with widths of 65 and $78 \mu \mathrm{m}$. Owing to the tight spatial constraints in front of the focal plane, it was not possible to provide a cover window over the CCD surface; the CCD system could not be evacuated and was cooled to $\sim 12^{\circ} \mathrm{C}$ by a Peltier cooler. One of the consequences of this is that the resultant spectra presented here have a pronounced background that is approximately some 5-8\% of the total intensity of the signal as a result of the dark current from these higher than normal operating temperatures.

The concentric components were initially aligned by adjusting the position of each component to optimise the detection of mercury emission lines, and the alignment refined through the use of an adapted autocollimator. For the initial alignment experiments light from an Ocean Optics HG1 Mercury Argon Calibration Source was passed through a $1 \mathrm{~mm}$ diameter optical fibre positioned approximately $30 \mathrm{~mm}$ from the centre of the entrance slit, such that the light filled the entrance slit. This light provided a means of checking the alignment of the instrument in terms of bandwidth covered by the focal plane, the focus of the instrument, the instrument line shape and wavelength calibration. The 65 and $78 \mu \mathrm{m}$ slits were fitted and experiments carried out with both using an integration time of one second. Through an iterative tuning process the spectrometer was optimised to record spectra showing the $365.02,366.33,404.66$, and $407.78 \mathrm{~nm}$ lines of the mercury spectrum, and on moving the CCD in the spectral domain the $435.84 \mathrm{~nm}$ line. It was possible to assess the instrument line shape by examining cut sections of the CCD image, such as those shown in Fig. 2 for the emission lines recorded using the $78 \mu \mathrm{m}$ slit. Each emission line was examined in detail with Fig. 3 showing the $365 \mathrm{~nm}$ peaks recorded using a slit width of 65 and $78 \mu \mathrm{m}$ respectively. The $65 \mu \mathrm{m}(0.065 \mathrm{~nm})$ slit offers a finer resolution, with a FWHM of between 4 and 5 pixels. Using the $78 \mu \mathrm{m}(0.078 \mathrm{~nm})$ slit the 365.02 and $365.48 \mathrm{~nm}$ lines could not be resolved, although the FWHM matched the expected 6-7 pixels for this slit width. Figure 3 also shows Gaussian fits made to each peak, generated with MicroCal Origin V6 software. The $R^{2}$ values for each fit are mostly in excess of 0.99 , confirming the stability of the Guassian line shape across the spectral domain, a key requirement for DOAS. Figure 4 shows similar plots with the 404 and $407 \mathrm{~nm}$ lines.

The wavelengths of the emission lines were attributed to the location of the peak centres on the CCD, and from this data a wavelength calibration for the instrument for both slit widths was determined, as given in Fig. 5. The calibration data demonstrates a strong linear relationship between the line position on the CCD and wavelength, with the data from the $65 \mu \mathrm{m}$ slit having a slightly better correlated linear fit than that from the $78 \mu \mathrm{m}$ slit. From this data it was possible to determine the spectral sampling characteristics for both slits: the effective sampling of the instrument with the $65 \mu \mathrm{m}$ $(0.065 \mathrm{~nm})$ slit was $0.07044 \mathrm{~nm} / \mathrm{pixel}$, and $0.07000 \mathrm{~nm} / \mathrm{pixel}$ with the $78 \mu \mathrm{m}(0.078 \mathrm{~nm})$ slit. The spectrometer bandwidth covered $150 \mathrm{~nm}$ in around 2150 pixels in a spatial distance of approximately $27.7 \mathrm{~mm}$, marginally larger than the design specification of $27.6 \mathrm{~mm}$. Applying the wavelength calibrations to the recorded data allowed evaluation of the spectral resolution of the recorded emission lines. Figure 6 shows the corresponding wavelength calibrated data recorded with the $65 \mu \mathrm{m}$ slit, with new Gaussian fits giving a spectral resolution of approximately $0.3 \mathrm{~nm}$. The corresponding spectral resolution for the $78 \mu \mathrm{m}$ slit was approximately $0.45 \mathrm{~nm}$. 

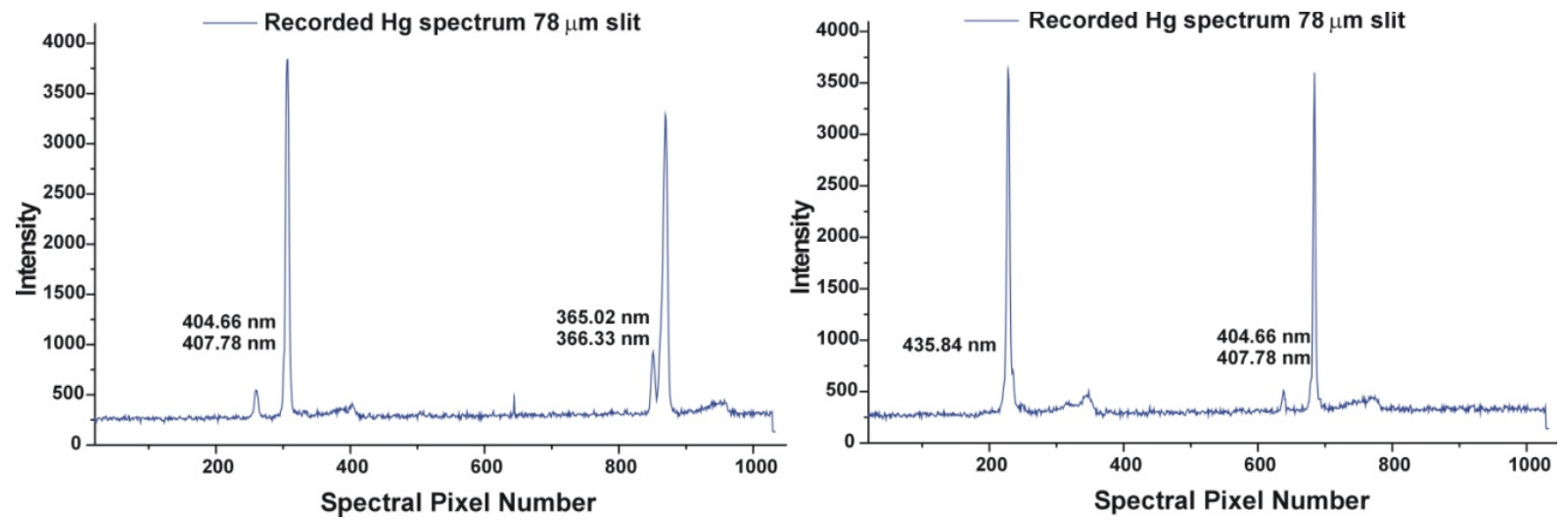

Fig. 2. The mercury line spectra recorded in the first light optimisation experiments for the $78 \mu \mathrm{m}$ slits.
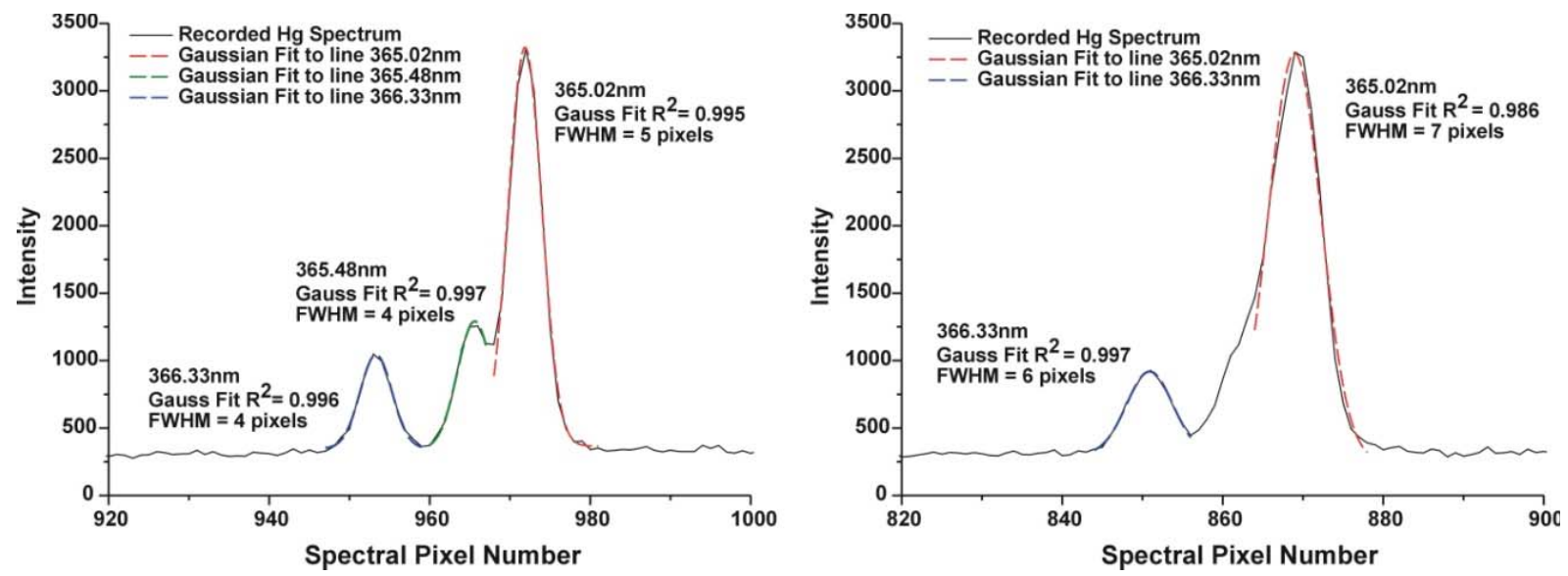

Fig. 3. A closer examination of the $365 \mathrm{~nm}$ lines recorded for slit widths of $65 \mu \mathrm{m}$ (left) and $78 \mu \mathrm{m}$ (right).
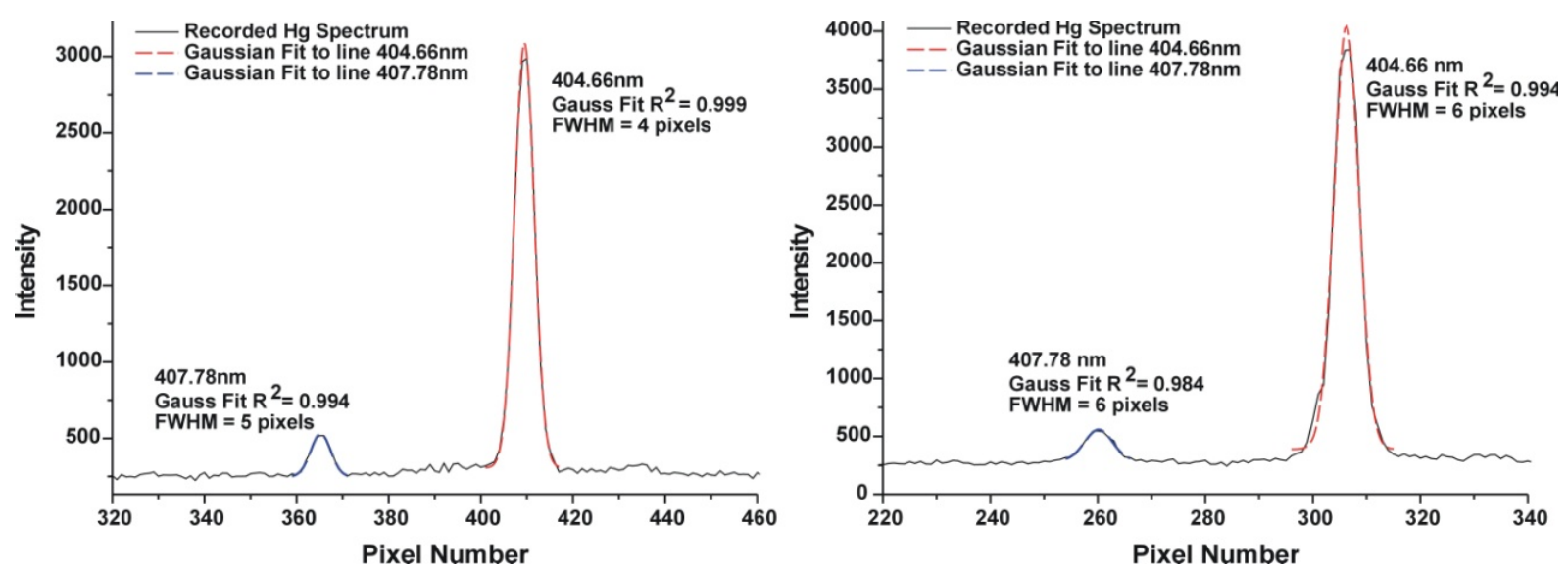

Fig. 4. A closer examination of the 404 and $407 \mathrm{~nm}$ line recorded for slit widths of $65 \mu \mathrm{m}$ (left) and $78 \mu \mathrm{m}$ (right). 

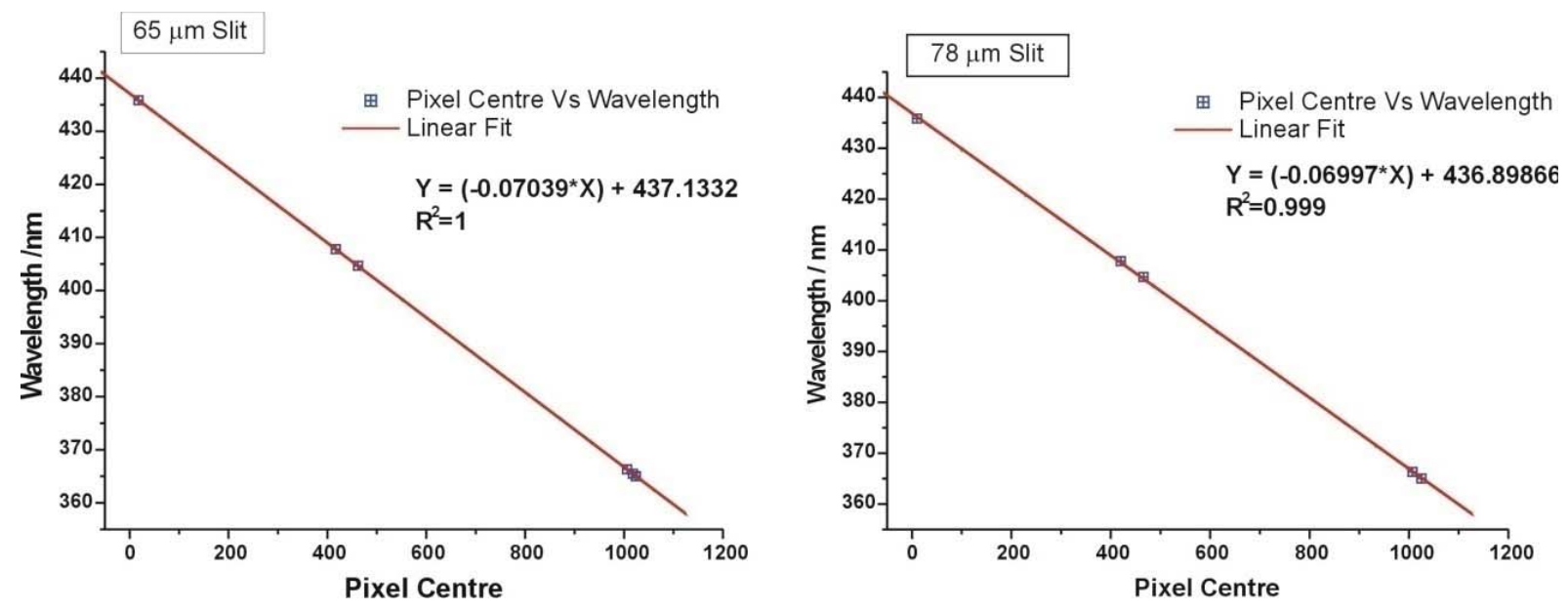

Fig. 5. Wavelength calibration plots for the $65 \mu \mathrm{m}$ slit (left) and the $78 \mu \mathrm{m}$ slit (right) showing the linear fit applied to each data set.
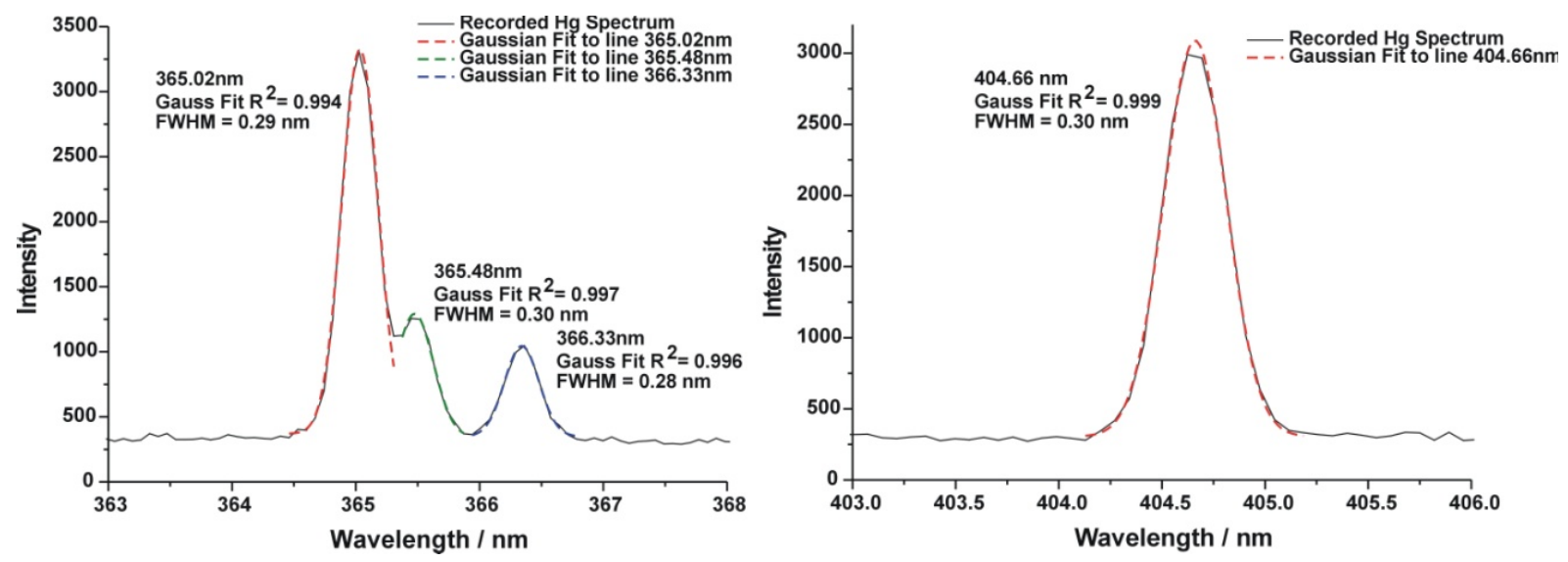

Fig. 6. Wavelength calibrated mercury emission lines with Gaussian fits applied to each emission line for data recorded with the $65 \mu \mathrm{m}$ slit.

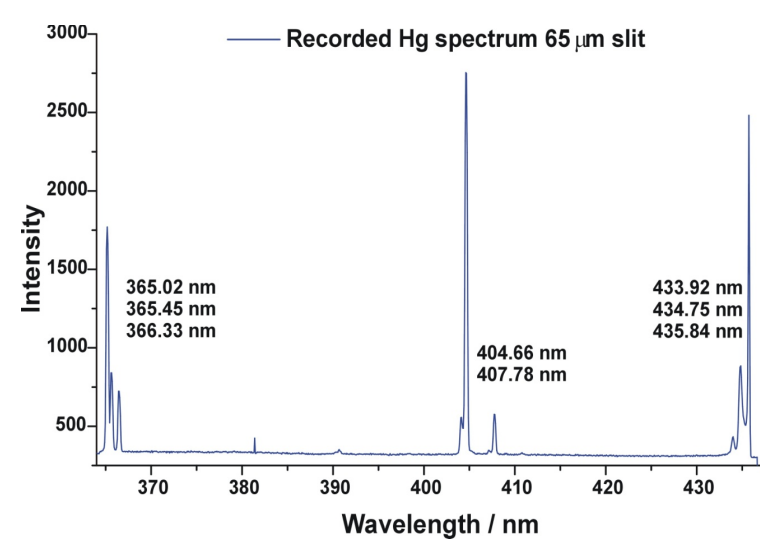

Fig. 7. An example of a mercury emission spectrum recorded from the CompAQS instrument with the alignment of the concentric optical components confirmed by optical methods using an autocollimator.
The spectral sampling was re-assessed using the autocollimator through a two step process. The autocollimator (Taylor Hobson, Microptic TA50 142/12) was fitted with an objective lens to focus the light emitted from the autocollimator. The autocollimator was adjusted to give a single point reflection from the grating surface, such that the point of focus was on the shared centre of curvature. The spherical meniscus lens was then introduced into the system and adjusted to give a coincident reflection from the meniscus lens front surface. The autocollimator was then moved and a single point reflection sought from the rear surface of the meniscus lens. The concave mirror was introduced and adjusted so as to give a coincident reflection. Once aligned the other components were fitted. Using the $65 \mu \mathrm{m}$ entrance slit spectra were recorded using a mercury lamp (Oriel 65160 with power supply 65150) positioned $30 \mathrm{~cm}$ from the entrance slit, passing through a diffuser prior to entering the spectrometer. Spectra were recorded in the same manner as before. A wavelength calibrated spectrum of emission lines from 

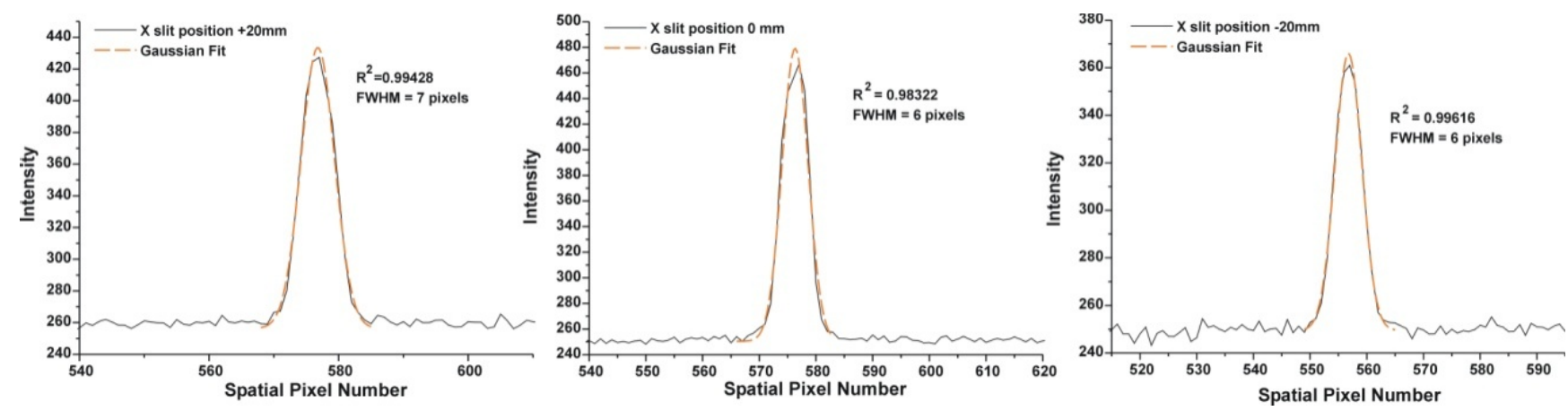

Fig. 8. A collection of the spatially resolved elements from the $404.66 \mathrm{~nm}$ mercury emission line for different locations of the entrance slit.

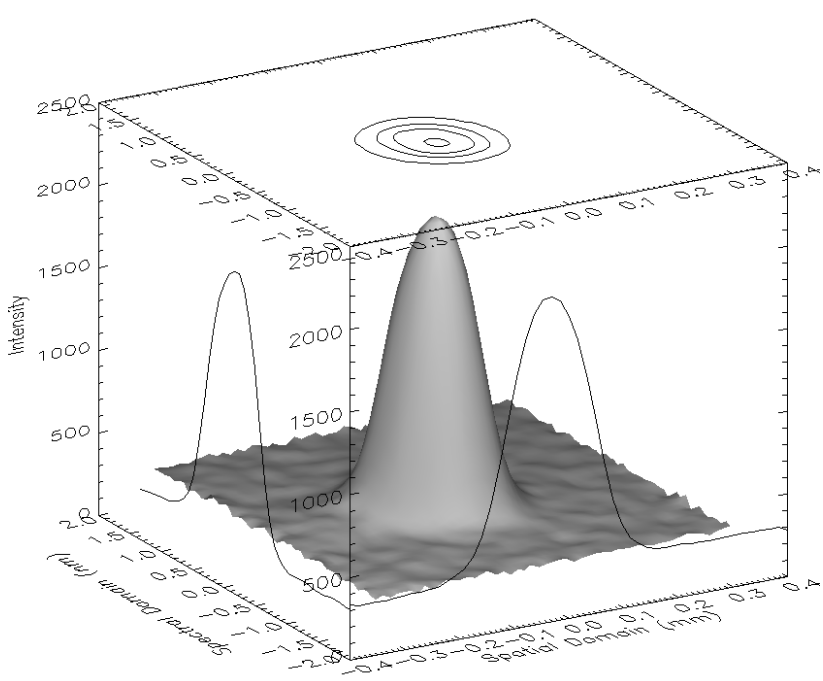

Fig. 9. A 3-D representation of the spatially resolved $404.66 \mathrm{~nm}$ mercury emission.

365.02-435.84 nm is shown in Fig. 7. As with the earlier optimisation method the emission lines were found to have a FWHM of 4 pixels $/ 0.3 \mathrm{~nm}$, with the Gaussian fits applied to the emission lines having a range of $R^{2}$ values between 0.95 and 0.99 .

The spatial sampling of the demonstrator was appraised by passing another slit of known width perpendicular to the entrance slit to create an entrance aperture of known dimensions. The resultant light on the focal plane covers a set number of pixels in the spatial domain equivalent to the width of the perpendicular slit. The same instrument configuration was used as before to allow for a direct comparison with the previous work to assess the spectral characteristics of the instrument. The $68 \mu \mathrm{m}$ slit was used as the entrance slit and a $91 \mu \mathrm{m}$ slit was used as the perpendicular slit for this experiment.

The perpendicular slit was placed at fixed points along the entrance slit relative to its centre $(-20 \mathrm{~mm},-10 \mathrm{~mm}, 0$, $+10 \mathrm{~mm},+20 \mathrm{~mm}$ from the centre) and measurements made.
The $404.66 \mathrm{~nm}$ emission line was the target for these experiments. With the perpendicular slit in place the emission line was found to retain the Gaussian spectral line shape with a consistent fitting $R^{2}$ value of 0.996 . Figure 8 shows the spatially resolved peaks from the same emission line at different points along the entrance slit. The FWHM for these peaks is 6 to 7 pixels. The individually resolved points were imaged in 3-D to appraise their shape, both spectrally and spatially, and the surrounding background levels of noise. Figure 9 shows such a plot for the $404.66 \mathrm{~nm}$ central spot.

With a spatial aperture of $91 \mu \mathrm{m}$ and a single pixel size of $13 \mu \mathrm{m}$ the FWHM of the spatially resolved element was confirmed as 7 pixels providing over 500 resolved elements over the $52 \mathrm{~mm}$ entrance slit. With the current focal plane size and appropriate entrance optics, a LEO system with a global coverage swath width of $2600 \mathrm{~km}$ would have a resultant spatial sampling of $650 \mathrm{~m}$, with an across-swath ground resolution of approximately $5 \mathrm{~km}$.

One key advantage of the concentric spectrometer design is the lack of curvature in the image of the entrance slit on the focal plane - the effect known as smile. A preliminary measurement of the smile of the CompAQS breadboard demonstrator was made by illuminating the full entrance slit with the Hg-Ar lamp. The resulting spectral line, imaged across the spatial domain was analysed for linearity across the detector. The results are shown in Fig. 10. Although some minor deviations from a linear response are suggested, the deviations are less than half of a $13 \mu \mathrm{m}$ pixel across the entire $13 \mathrm{~mm}$ CCD surface.

Although entrance optics were not incorporated into the CompAQS demonstrator, a rudimentary system was tested using a fibre optic input and convex lenses to image scattered sunlight into the CompAQS instrument. The resulting spectrum is given in Fig. 11, plotted with a Kurucz solar spectrum. Using the established WinDOAS analysis package, the FWHM of this spectrum was measured at $0.55 \mathrm{~nm}$, with a linear wavelength calibration confirming the sampling of $0.0705+/-0.001 \mathrm{~nm} /$ pixel. 


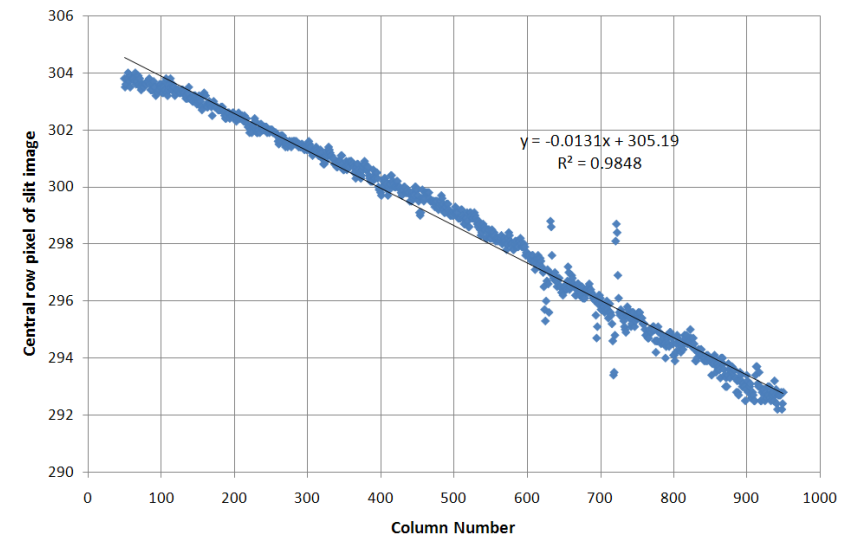

Fig. 10. A measurement of the "smile" in the CompAQS spectrometer system. The overall slope of the plot is due to a minor rotation of the CCD detector with respect to the focal plane. Sub-pixel values were obtained using a combined smoothing/spline interpolation routine. Features around column 620 and 710 result from artefacts on the CCD surface, and not deviation of the image.

A preliminary evaluation of the instrument stray light was performed to investigate the proportion of the upper bandwidth radiation incident upon the lower bandwidth (UV) portion of the focal plane. Light from a $200 \mathrm{~W}$ QTH lamp was passed through an Oriel Cornerstone 260 monochromator, providing fixed wavelengths representative of the upper bandwidth of the CompAQS instrument. Measurements of the intensity were made by moving the CCD in the spectral domain to a position corresponding to the upper limit of the bandwidth. To prevent saturation of the CCD the light from the lamp was first passed through a series of neutral density filters $(0.9,0.6$ and $0.4 \mathrm{OD})$. The light from the monochromator was focussed into the instrument using a set of two convex lenses. Measurements were made with 10, 30 and $60 \mathrm{~s}$ integration times. Repeat measurements were made using the same procedure, without the neutral density filters, and the CCD positioned to sample the lower end of the bandwidth to detect the stray light. On completion all lights were turned off and measurements made to measure the instrument dark signal.

The dark noise image was subtracted from both the stray light and full intensity images, and the resultant full intensity images were scaled to account for the filters. The stray light images were then evaluated as a percentage of the full intensity, presented as 2-D maps in Fig. 12. The intense signal observed in the upper right corner has been attributed to an observed light leak at the apex of the conical baffle where the entrance slit sits. This is corroborated by the signal not moving in the spectral domain with changing wavelength, and the signal is observed for all wavelengths. The small random single pixel peaks that can also be seen have been attributed to "hot" pixels in the detector. To account for these features both the upper portion and the hot pixels were ex-

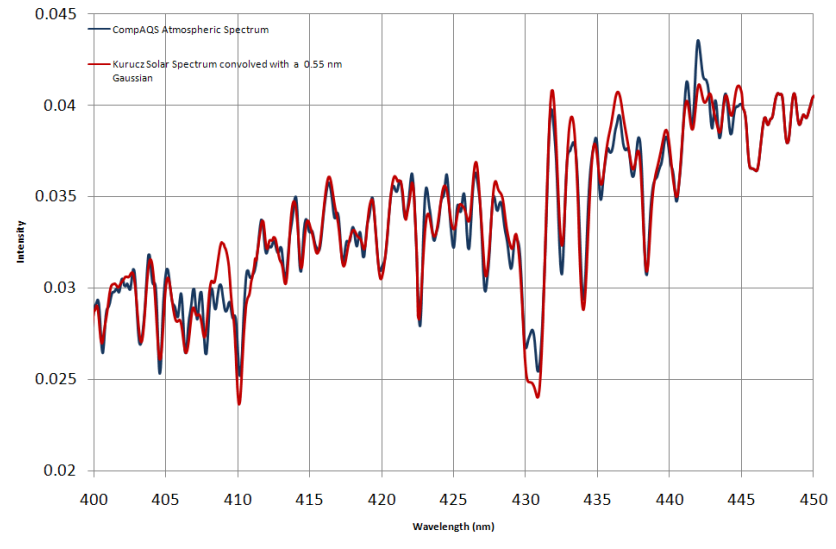

Fig. 11. Example atmospheric spectrum from the CompAQS instrument, plotted with a convolved Kurucz solar spectrum at $0.55 \mathrm{~nm}$.

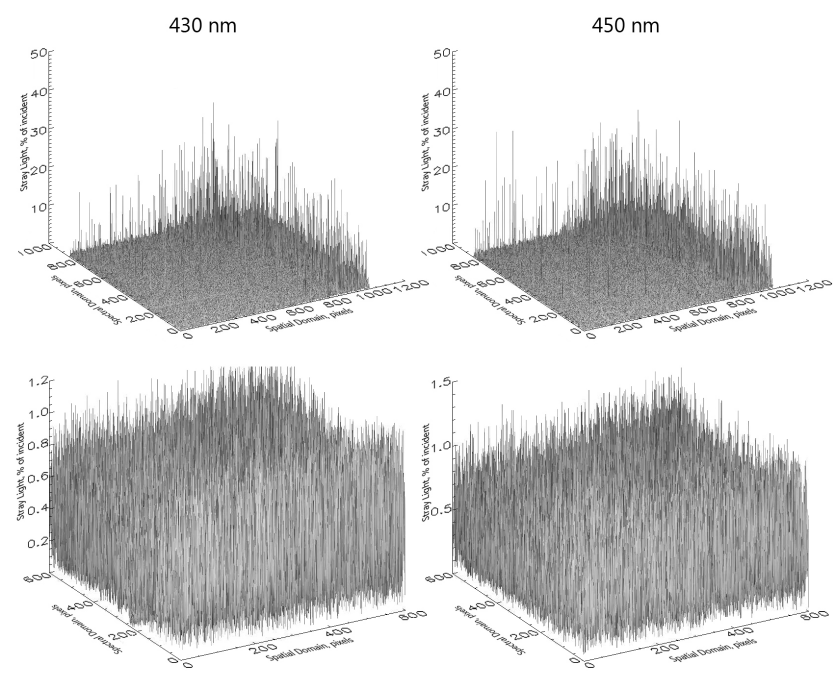

Fig. 12. Example stray light maps using $10 \mathrm{~s}$ integration time for 430 and $450 \mathrm{~nm}$. The upper right portion is attributed to an observed light leak around the entrance slit, which was not observed to shift in the spectral domain with increasing wavelength. Removing this from the analysis yields the image maps given in the lower portion of the figure.

cluded. Resultant stray light is derived from the mean of the pixel values, (Table 3) which is observed to increase with increasing wavelength to a maximum of $0.43 \%$ at $450 \mathrm{~nm}$. While this is higher than the ideal standard of $0.01 \%$, these values represent only an initial value, and there are several factors that could continue to influence this value which need to be explored. First, the demonstrator unit did not feature dedicated baffles, which are traditionally the most effective means for reducing stray light within an instrument. Secondly, the entire spatial domain was not sampled and as such this represents only a snapshot of the possible stray light. Lastly, the optical components do not represent the quality that would be utilised in a space instrument, and therefore 
Table 3. Preliminary measurements of the instrument stray light with wavelengths representing the critical upper portion of the instrument bandwidth. These values represent the mean of the measurements made with the integration times of 10,30 and $60 \mathrm{~s}$, with the value in brackets representing the standard deviation in the measurements.

\begin{tabular}{lccccc}
\hline Wavelength / nm & 410 & 420 & 430 & 440 & 450 \\
Stray light / \% & $0.362(0.028)$ & $0.385(0.006)$ & $0.391(0.05)$ & $0.387(0.001)$ & $0.430(0.005)$
\end{tabular}

the current components will increase the overall propensity for stray light within the instrument. Therefore these values should be considered as a maximum upper limit to the possible stray light within the instrument. Owing to the problems wrought by the current entrance system a new design of the spectrometer featuring a dedicated entrance telescope that removes both the large entrance baffle and fold mirror is nearing completion, which should ably decrease the stray light from outside the instrument. It should also be noted that a future space based mission using the concentric spectrometer design would mostly be split into a dual channel instrument for UV and Visible applications, removing the tight stray light constraints on the instrument. Despite being larger than the target value, the maximum of $0.43 \%$ represents a viable starting value for the current demonstrator and therefore, even at this preliminary stage of development, CompAQS should be a powerful tool for future DOAS work.

\section{Conclusions}

The concentric spectrometer (CompAQS) concept theoretically offers exceptional spatial and spectral performance at very low volume and weight budgets, and the demonstrator has confirmed those key features: the volume of the optical components and focal plane in the demonstrator is little bigger than $20 \mathrm{~cm}^{3}$, and the instrument provides sufficiently high spectral and spatial sampling intervals to allow for oversampling factors of 7 pixels with a relatively high spectral resolution of $0.5 \mathrm{~nm}$ and $5 \mathrm{~km}$ across-track spatial resolution. The instrument line shape has been characterised and shown to approximate a Gaussian profile with measured $R^{2}$ values typically in excess of 0.99 . Another key characteristic of the concentric concept was the self-correction of instrument "smile", which was demonstrated to be negligible. The instrument has been found to be relatively straight forward to align and tune, with the concentric design making the alignment of the components reasonably forgiving for such a high performance system: alignment within $0.5 \mathrm{~mm}$ provides spectral and spatial properties very near target specifications. The measurement of the atmospheric spectrum has also shown the potential of this spectrometer for DOAS applications when coupled with appropriate entrance optics.

Another significant output is the demonstration that the optical components for this type of spectrometer, principally the diffraction grating, can be manufactured to the necessary specification. The total integrated scatter from this critical part was found to be exceptionally good when considering that this component is the first of its kind, ranging from approximately $0.15 \%$ at $300 \mathrm{~nm}$ to $0.07 \%$ at $450 \mathrm{~nm}$. It is envisaged that a future space system built on this design would be half the size of the current demonstrator system, making it even lighter and compact, while still maintaining the same spatial and spectral capabilities as the demonstrator.

Acknowledgements. The authors would like to thank all the manufacturers of the components for their efforts on delivering the items to the specification and to the dedication of the university workshops in providing the substructure of the instrument. This work was funded by the NERC/TSB Centre for Earth Observation Instrumentation.

Edited by: J. Stutz

\section{References}

Aliwell, S. R., Van Roozendael, M., Johnston, P. V., Richter, A., Wagner, T., Arlander, D. W., Burrows, J. P., Fish, D. J., Jones, R. L., Tornkvist, K. K., Lambert, J. C., Pfeilsticker, K., and Pundt, I.: Analysis for $\mathrm{BrO}$ in zenith-sky spectra: An intercomparison exercise for analysis improvement, J. Geophys. Res.-Atmos., 107, 4199, doi:10.1029/2001JD000329, 2002.

Axelsson, H., Edner, H., Galle, B., Ragnarson, P., and Rudin, M.: Differential Optical-Absorption Spectroscopy (DOAS) measurements of ozone in the $280-290 \mathrm{~nm}$ wavelength region, Appl. Spectrosc., 44, 1654-1658, 1990.

Bobrowski, N., Hönninger, G., Galle, B., and Platt, U.: Detection of bromine monoxide in a volcanic plume, Nature, 423, 273-276, doi:10.1038/nature01638, 2003.

Bobrowski, N. and Platt, U.: $\mathrm{SO}_{2} / \mathrm{BrO}$ ratios studied in five volcanic plumes, J. Volcanol. Geoth. Res., 166, 147-160, doi:10.1016/j.jvolgeores.2007.07.003, 2007.

Bonay, M. and Aubier, M.: Air pollution and allergic airway diseases, M. S-Med. Sci., 23, 187-192, 2007.

Bovensmann, H., Noël, S., Goede, A. P. H., and Burrows, J. P.: The Geostationary Scanning Imaging Absorption Spectrometer (GeoSCIA) mission: Requirements and Capabilities, Adv. Space Res., 29, 1849-1859, 2002.

Burrows, J. P.: Geotrope: Geostationary tropospheric pollution explorer. Tropospheric pollution monitoring on a regional scale, University of Bremen, CNRS - Universite Paris-Sud, University of Leicester, KNMI, Forschungszentrum Karlsruhe/IMK FZK, 
Astrium, OHB-System, TPD-TNO. SIRA Ltd, The GeoTROPE Science Team, 194, 2005.

Cai, X. M., Zheng, Y., and McGregor, G. R.: Modelling of meteorological conditions at an urban scale for the PUMA winter campaign, Phys. Chem. Earth., 27, 1479-1485, 2002.

Callies, J., Corpaccioli, E., Eisinger, M., Hahne, A., and Lefebvre, A.: GOME-2 - Metop's Second-Generation Sensor for Operational Ozone Monitoring, ESA Bull., 102, 28-36, 2000.

Cardenas, L. M., Brassington, D. J., Allan, B. J., Coe, H., Alicke, B., Platt, U., Wilson, K. M., Plane, J. M. C., and Penkett, S. A.: Intercomparison of formaldehyde measurements in clean and polluted atmospheres, J. Atmos. Chem., 37, 53-80, 2000.

Chance, K., Palmer, P. I., Spurr, R. J. D., Martin, R. V., Kurosu, T. P., and Jacob, D. J.: Satellite observations of formaldehyde over North America from GOME, Geophys. Res. Lett., 27, 34613464, 2000.

D'Amato, G., Liccardi, G., D'Amato, M., and Holgate, S.: Environmental risk factors and allergic bronchial asthma, Clin. Exp. Allergy, 35, 1113-1124, 2005.

DEFRA: UK Air Quality Archive, 2007.

Edner, H., Ragnarson, P., Spannare, S., and Svanberg, S.: Differential Optical-Absorption Spectroscopy (DOAS) system for urban atmospheric-pollution monitoring, Appl. Optics, 32, 327-333, 1993.

Eskes, H., Tanskanen, A., Elbern, H., Buchwitz, M., Meirink, J. F., de Leeuw, G., Bovensmann, H., Valks, P., Meerkotter, R., Staiger, H., Fanton d'Andon, O., Kilbane Dawe, I., Holzer-Popp, T., Kyrola, E., Flaud, J.-M., Baier, F., Erbertseder, T., van Weele, M., and Flore, F.: S3 service prospectus, 2006.

Evangelisti, F., Baroncelli, A., Bonasoni, P., Giovanelli, G., and Ravegnani, F.: Differential Optical-Absorption Spectrometer for measurement of tropospheric pollutants, Appl. Optics, 34, 27372744, 1995.

Flynn, L. E., Seftor, C. J., Larsen, J. C., and Xu, P.: The Ozone Mapping and Profiler Suite (OMPS), NOAA Satellite and Information Services, 2005.

Friess, U., Wagner, T., Pundt, I., Pfeilsticker, K., and Platt, U.: Spectroscopic measurements of tropospheric iodine oxide at Neumayer station, Antarctica, Geophys. Res. Lett., 28, 19411944, 2001.

Friess, U., Kreher, K., Johnston, P. V., and Platt, U.: Ground-based DOAS measurements of stratospheric trace gases at two Antarctic stations during the 2002 ozone hole period, J. Atmos. Sci., 62, 765-777, 2005.

Friess, U., Monks, P. S., Remedios, J. J., Rozanov, A., Sinreich, R., Wagner, T., and Platt, U.: Max-DOAS $\mathrm{O}_{4}$ measurements: A new technique to derive information on atmospheric aerosols: 2. Modelling studies, J. Geophys. Res-Atmos., 111, D14203 doi:10.1029/2005jd006618, 2006.

Galan, I., Tobias, A., Banegas, J. R., and Aranguez, E.: Short-term effects of air pollution on daily asthma emergency room admissions, Eur. Respir. J., 22, 802-808, 2003.

Graf, P. H., Becker, I., Chrisp, M., Dittman, M., Fowler, W., Hendershott, P., Jaross, G., Larsen, J., Mehalko, P., Michaels, D., Minerva, V., Qu, J., Rathburn, R., Rodriguez, J. V., Seftor, C., Schwiesow, R., Snell, H. F., Swissler, T. J., Tarde, R., and Wellemeyer, C.: The Preliminary Design of the Ozone Mapping and Profiler Suite, NOAA Satellite and Information Service, 1999.

Harrison, R. M., Yin, J., Tilling, R. M., Cai, X., Seakins, P. W.,
Hopkins, J. R., Lansley, D. L., Lewis, A. C., Hunter, M. C., Heard, D. E., Carpenter, L. J., Creasy, D. J., Lee, J. D., Pilling, M. J., Carslaw, N., Emmerson, K. M., Redington, A., Derwent, R. G., Ryall, D., Mills, G., and Penkett, S. A.: Measurement and modelling of air pollution and atmospheric chemistry in the UK West Midlands conurbation: Overview of the PUMA consortium project, Sci. Total Environ., 360, 5-25, 2006.

Hastings, W. P., Koehler, C. A., Bailey, E. L., and De Haan, D. O.: Secondary organic aerosol formation by glyoxal hydration and oligomer formation: Humidity effects and equilibrium shifts during analysis, Envir. Sci. Tech., 39, 8728-8735, 2005.

Hönninger, G. and Platt, U.: Observations of $\mathrm{BrO}$ and its vertical distribution during surface ozone depletion at Alert, Atmos. Environ., 36, 2481-2489, 2002.

Hönninger, G., von Friedeburg, C., and Platt, U.: Multi axis differential optical absorption spectroscopy (MAX-DOAS), Atmos. Chem. Phys., 4, 231-254, 2004, http://www.atmos-chem-phys.net/4/231/2004/.

Kelder, H., van Weele, M., Goede, A., Kerridge, B., Reburn, J., Bovensmann, H., Monks, P., Remedios, J., Mager, R., Sassier, H., and Baillon, Y.: Operational Atmospheric Chemistry Monitoring Missions, European Space Agency 2005.

Kim, D. H., Kim, Y. S., Park, J. S., Kwon, H. J., Lee, K. Y., Lee, S. R., and Jee, Y. K.: The effects of on-site measured ozone concentration on pulmonary function and symptoms of asthmatics, J. Korean Med. Sci., 22, 30-36, 2007.

Kim, S. W., Yoon, S. C., Won, J. G., and Choi, S. C.: Ground-based remote sensing measurements of aerosol and ozone in an urban area: A case study of mixing height evolution and its effect on ground-level ozone concentrations, Atmos. Environ., 41, 70697081, doi:10.1016/j.atmosenv.2007.04.063, 2007.

Kramer, L. J., Leigh, R. J., Remedios, J. J., and Monks, P. S.: Comparison of OMI and ground-based in situ and MAX-DOAS measurements of tropospheric nitrogen dioxide in an urban area, J. Geophys. Res.-Atmos., 113, D16S39, doi:10.1029/2007jd009168, 2008.

Kuhl, S., Wilms-Grabe, W., Frankenberg, C., Grzegorski, M., Platt, U., and Wagner, T.: Comparison of $\mathrm{OClO}$ nadir measurements from SCIAMACHY and GOME, Atmospheric Remote Sensing: Earth's Surface, Troposphere, Stratosphere and Mesosphere-Ii, 37, 2247-2253, doi:10.1016/j.asr.2005.06.061, 2006.

Langen, J.: GMES Sentinels 4 and 5 Mission Requirements Documents, European Space Agency EOP-SMA/1507/JL-dr, 2007.

Lee, J. S., Kim, Y. J., Kuk, B., Geyer, A., and Platt, U.: Simultaneous measurements of atmospheric pollutants and visibility with a long-path DOAS system in urban areas, Environmental Monitoring and Assessment, 104, 281-293, doi:10.1007/s10661-0051616-6, 2005.

Leser, H., Hönninger, G., and Platt, U.: MAX-DOAS measurements of $\mathrm{BrO}$ and $\mathrm{NO}_{2}$ in the marine boundary layer, Geophys. Res. Lett., 30, 1537, doi:10.1029/2002g1015811, 2003.

Lobb, D.: Theory of concentric designs for grating spectrometers, Appl. Optics, 33, 2648-2658, 1994.

Lobb, D.: Design of a spectrometer system for measurements on earth atmosphere from geostationary orbit, in: Procedings of SPIE optical design and engineering, edited by: Mazura, L., Rogers, P. J., and Wartmann, R., SPIE, 191-202, 2004.

Lohberger, F., Hönninger, G., and Platt, U.: Ground-based imaging differential optical absorption spectroscopy of atmospheric 
gases, Appl. Optics, 43, 4711-4717, 2004.

Louban, I., Piriz, G., Platt, U., and Frins, E.: Differential optical absorption spectroscopy (DOAS) using targets: $\mathrm{SO}_{2}$ and $\mathrm{NO}_{2}$ measurements in Montevideo city, Riao/Optilas 2007, 992, 2126, 2008.

MacNee, W. and Donaldson, K.: Exacerbations of COPD - environmental mechanisms, Chest, 117, 390S-397S, 2000.

Mihailovic, D. T., Rao, S. T., Alapaty, K., Ku, J. Y., Arsenic, I., and Lalic, B.: A study on the effects of subgrid-scale representation of land use on the boundary layer evolution using a 1-d model, Environ. Modell. Softw., 20, 705-714, 2005.

Munro, R. and Eisinger, M.: GOME-2 Level 1 Product Generation Specification, EUMETSAT, Darmstadt, Germany, 2006.

Owen, B., Edmunds, H. A., Carruthers, D. J., and Raper, D. W.: Use of a new generation urban scale dispersion model to estimate the concentration of oxides of nitrogen and sulphur dioxide in a large urban area, Sci. Total Environ., 235, 277-291, 1999.

Palazzi, E., Petritoli, A., Ravegnani, F., Kostadinov, I., Bortoli, D., Masieri, S., Premuda, M., and Giovanelli, G.: Multiple axis DOAS measurements for the retrieval of nitrogen dioxide and ozone vertical profiles in the Presidential estate of Castel Porziano (Rome) - art. No. 67451y, Conference on Remote Sensing of Clouds and the Atmosphere XII, Florence, ISI:000253868600053, Y7451-Y7451, ITALY, 2007.

Peel, J. L., Metzger, K. B., Klein, M., Flanders, W. D., Mulholland, J. A., and Tolbert, P. E.: Ambient air pollution and cardiovascular emergency department visits in potentially sensitive groups, Am. J. Epidemiol., 165, 625-633, 2007.

Platt, U.: Differential Optical Absorption Spectroscopy, (DOAS), in air monitoring by spectroscopic techniques, in: Chemical analysis, edited by: Sigrist, M. W., Wiley, New York, 1994.

Prieto-Blanco, X., Montero-Orille, C., Couce, B., and de la Fuente, R.: Analytical design of an Offner imaging spectrometer, Opt. Express, 14, 9156-9168, 2006.

Pundt, I., Mettendorf, K. U., Laepple, T., Knab, V., Xie, P., Losch, J., Friedeburg, C. V., Platt, U., and Wagner, T.: Measurements of trace gas distributions using long-path DOAStomography during the motorway campaign BAB II: Experimental setup and results for $\mathrm{NO}_{2}$, Atmos. Environ., 39, 967-975, doi:10.1016/j.atmosenv.2004.07.035, 2005.

Rage, E., Siroux, V., Pin, I., and Kauffmann, F.: Effect of ozone exposure on asthma severity, lung function and bronchial responsiveness in 371 adult asthmatics from the EGEA study, Epidemiology, 17, S287-S287, 2006.

Richter, A., Eisinger, M., Ladstatter-Weissenmayer, A., and Burrows, J. P.: DOAS zenith sky observations: 2. Seasonal variation of BrO over Bremen (53 degrees N) 1994-1995, J. Atmos. Chem., 32, 83-99, 1999.
Rodriguez, J. V., Seftor, C. J., Wellemeyer, C. G., and Chance, K.: Overview of the nadir sensor and algorithm for OMPS, NOAA Satellite and Information Services, 2002.

Sinreich, R., Friess, U., Wagner, T., and Platt, U.: Multi axis differential optical absorption spectroscopy (MAX-DOAS) of gas and aerosol distributions, Faraday Discuss., 130, 153-164, doi:10.1039/b419274p, 2005.

Stuhlmann, R., Rodriguez, A., Tjemkes, S., Grandell, J., Arriaga, A., Bézy, J.-L., Aminou, D., and Bensi, P.: Plans for EUMETSAT's third generation Meteosat geostationary satellite programme, Adv. Space Res., 36, 975-981, 2005.

Tornkvist, K. K., Arlander, D. W., and Sinnhuber, B.-M.: Groundbased UV measurements of $\mathrm{BrO}$ and $\mathrm{OClO}$ over $\mathrm{Ny}$-Alesund during winter 1996 and 1997 and Andoya during winter 1998/99, J. Atmos. Chem., 43, 75-106, 2002.

Van der A, R., Bhartia, P. K., Boersma, F., Brinksma, E., Carpay, J., Chance, K., de Haan, J., Hilsenrath, E., Isaksen, I., Kelder, H., Leppelmeier, G. W., Levelt, P. F., Mälkki, A., McPeters, R. D., Noordhoek, R., Van den Oord, G. H. J., Van Oss, R., Piters, A., Snel, R., Stammes, P., Valks, P., Veefkind, J. P., van Velthoven, P., Voors, R., and Van Weele, M.: Science Requirements Document for OMI-EOS, KNMI, De Bilt, 2000.

Van Roozendael, M., Hermans, C., Demaziere, M., and Simon, P. C.: Stratospheric $\mathrm{NO}_{2}$ observations at the Jungfraujoch station between June 1990 and May 1992, Geophys. Res. Lett., 21, 1383-1386, 1994.

Veitel, H., Kromer, B., Mossner, M., and Platt, U.: New techniques for measurements of atmospheric vertical trace gas profiles using DOAS, Environ. Sci. Pollut. R., 4, 17-26, 2002.

Virkkula, A.: Performance of a Differential Optical Absorption Spectrometer for surface $\mathrm{O}_{3}$ measurements in the Finnish Arctic, Atmos. Environ., 31, 545-555, 1997.

Wagner, T., Dix, B., von Friedeburg, C., Friess, U., Sanghavi, S., Sinreich, R., and Platt, U.: MAX-DOAS $\mathrm{O}_{4}$ measurements: A new technique to derive information on atmospheric aerosols - principles and information content, J. Geophys. Res.-Atmos., 109, D22205, doi:10.1029/2004jd004904, 2004.

Wang, S., Ackermann, R., and Stutz, J.: Vertical profiles of $\mathrm{O}_{3}$ and $\mathrm{NO}_{\mathrm{x}}$ chemistry in the polluted nocturnal boundary layer in Phoenix, AZ: I. Field observations by long-path DOAS, Atmos. Chem. Phys., 6, 2671-2693, 2006, http://www.atmos-chem-phys.net/6/2671/2006/.

Wayne, R. P.: Chemistry of atmospheres, 3rd Edn., Oxford University Press, Oxford, 2000.

Wittrock, F., Muller, R., Richter, A., Bovensmann, H., and Burrows, J. P.: Measurements of iodine monoxide (IO) above Spitsbergen, Geophys. Res. Lett., 27, 1471-1474, 2000. 